\title{
Inhalt
}

Grußwort — V

Anna Margaretha Horatschek

Vorwort — IX

Anna Margaretha Horatschek und Anja Pistor-Hatam

Einleitung - 1

Identitätsdebatten in Philosophie und Literatur

Julian Wolfreys

Es gibt keinen Staat or, Europe, the very idea

(Identity in Crisis to be Announced) -15

Jürgen Schlaeger

Identitätskonzepte im Spannungsfeld von Segmentierung und Proliferation — 27

Anna Margaretha Horatschek

Identität als Fiktion im britischen Roman der Gegenwart - 40

Ulrike Jekutsch

Entwürfe regionaler Identität in der polnischen Literatur nach 1990 - am Beispiel Niederschlesiens -63

Klavdia Smola

Jüdische Identität in der Sowjetunion und Mimikry:

Geschichte, Kultur, Literatur -86

\section{Europäische Identitäten}

Christian Jansen

„Verspätet?“ - „Pünktlich?“ - „Zu früh?“

Klischees, Thesen und Forschungsfelder zur Nationsbildung in Europa während des 19. Jahrhunderts $-\mathbf{1 0 7}$

Gabriele Clemens

„Après avoir créé un commencement d'Europe, il nous faut des Européens“

Die Konstruktion einer europäischen Identität durch Europawerbefilme — 118 
Wolfgang Kaschuba

Wahlverwandtschaften? Alte Zugehörigkeiten und neue Zuordnungen in Europa - 137

Silke Göttsch-Elten

Deutsch oder Dänisch?

Kulturelle Vielfalt als nationale Differenz in der Grenzregion Schleswig um $1900 \longrightarrow 150$

\section{Außereuropäische Kontexte}

Bernd Simon

Duale Identität im Kontext von Migration — 169

Dirk Nabers

Identität und Krise in den Internationalen Beziehungen (IB): Das Fallbeispiel des amerikanischen war on terror -182

Anja Pistor-Hatam

Aspekte kollektiver iranischer Identität im Zeitalter des Nationalismus - 201

Bibliographie -216

Beiträgerinnen und Beiträger — 232

Personenregister -235

Sachregister -241 